\title{
A regional Stokes-Helmert geoid determi- nation for Costa Rica (GCR-RSH-2020): computation and evaluation
}

\author{
Jaime GARBANZO-LEÓN ${ }^{1, *}$ (D), Alonso VEGA FERNÁNDEZ ${ }^{1}$ (D), \\ Mauricio VARELA SÁNCHEZ ${ }^{1}$ (D), Juan Picado SALVATIERRA ${ }^{1}$ (D), \\ Robert W. KINGDON², Oscar H. LÜCKE ${ }^{3}$ (D) \\ ${ }^{1}$ School of Surveying Engineering, University of Costa Rica \\ ${ }^{2}$ School of Geodesy and Geomatics Engineering, University of New Brunswick \\ ${ }^{3}$ Central American School of Geology of the University of Costa Rica
}

\begin{abstract}
GNSS observations are a common solution for outdoor positioning around the world for coarse and precise applications. However, GNSS produces geodetic heights, which are not physically meaningful, limiting their functionality in many engineering applications. In Costa Rica, there is no regional model of the geoid, so geodetic heights (h) cannot be converted to physically meaningful orthometric heights $(H)$. This paper describes the computation of a geoid model using the Stokes-Helmert approach developed by the University of New Brunswick. We combined available land, marine and satellite gravity data to accurately represent Earth's high frequency gravity field over Costa Rica. We chose the GOCO05s satellite-only global geopotential model as a reference field for our computation. With this combination of input data, we computed the 2020 Regional Stokes-Helmert Costa Rican Geoid (GCR-RSH-2020). To validate this model, we compared it with 4 global combined geopotential models (GCGM): EGM2008, Eigen6C-4, GECO and SGG-UM-1 finding an average difference of $5 \mathrm{~cm}$. GECO and SGG-UM-1 are more similar to the GCR-RSH-2020 based on the statistics of the difference between models and the shape of the histogram of differences. The computed geoid also showed a shift of $7 \mathrm{~cm}$ when compared to the old Costa Rican height system but presented a slightly better fit with that system than the other models when looking at the residuals. In conclusion, GCR-RSH-2020 presents a consistent behaviour with the global models and the Costa Rican height systems. Also, the lowest variance suggests a more accurate determination when the bias is removed.
\end{abstract}

Key words: heights, geoid, gravity, Stokes-Helmert approach, Costa Rica

\section{Introduction}

GNSS observations are a common solution for outdoor positioning around

\footnotetext{
*corresponding author: e-mail: jaimegarbanzo@gmail.com
} 
the world and are used for height determination in other mapping techniques such as photogrammetry and LiDAR. The latitude and longitude are determined accurately by GNSS for precise applications, but the orthometric heights for some science and engineering applications can only be determined if geoid heights are also available in the area of interest. A geoid height $(N)$ is the correction needed for the geodetic height from GNSS to be transformed to the orthometric height $(H)$. The quantity $N$ is the height of the geoid reference surface above the reference ellipsoid. Thus, the accurate computation of the geoid is of great importance in the development of a region. Until today, there is no official determination of a geoid for Costa Rica and the $H$ determination had to rely in global geoid models, which have a low spatial resolution and lack the contributions of high density ground based gravity stations to the high frequency gravity spectrum since the ground data in global models is gridded and decimated. This paper shows the efforts of the University of Costa Rica to provide a valid and traceable solution to this problem. This project also had the support of the University of New Brunswick, which allows the computation of a geoid using the Stokes-Helmert technique developed in this institution.

First, this document shows a literature review some of the efforts made for the geoid determination. Next, we describe some of the developments achieved in satellite gravity modelling and the Stokes-Helmert technique. After that, we discuss the land gravimetric campaigns of the historic gravity databases available for the computation. We explain in the method section the data quality testing for land and marine gravity data, the basis of the Stokes-Helmert Technique, the gravity interpolation process, and other parameter choice for the computation. Finally, we focus on the comparison between the global geoid models (GGM) and the computed geoid, and validation using 25 GNSS points associated with vertical benchmarks. This last validation suggests that the computed geoid describes the reference surface in Costa Rica better than the global geoid models.

\section{Literature review}

In Costa Rica, there have been few attempts to compute a regional geoid model (Cordero Gamboa, 2010; Moya Zamora and Dörries, 2004). More recently, Varela Sánchez (2018) computed a regional gravimetric geoid using 
historical databases provided by the National Geographic Institution (IGN). However, these gravimetric databases do not contain detailed comprehensive compilation of all the available historical data and did not include a rigorous quality assessment and outlier removal process. Also, marine and satellite altimetry data were not included in the computation.

Gravity studies in Costa Rica began since 1916 for oil and gas prospecting (Ballestero et al., 1995). The first published data is from 1958 (Monges, 1958). The International Gravity Standardization Network (IGSN71) included 2 points (Point \# 00994K and 00994L) in the country (Morelli et al., 1972), which served as reference points for densification, but these points are now destroyed. Also, geophysical studies have been a provider of gravity values, including those from de Boer (1974), Barritt and Berrangé (1987), Gurney (1997) and many others. This data is accumulated in different databases, which sometimes are duplicated, and its quality is not checked. For example, Institutions such as the Bureau Gravimetrique International (BGI) and the National Geospatial Intelligence Agency of the United States (NGA) hold large amounts of terrestrial and marine data, which must be thoroughly filtered. Most recently, New high quality terrestrial gravity data is being acquired, for example by Lücke (2018) and Denyer et al. (2019). The variety of datasets requires paying special attention on the interpolation approach.

The fundamental theory behind the Stokes-Helmert approach of performing the Stokes integration in the Helmert space was introduced by Vaniček and Kleusberg (1987). Since this time, the approach is being perfected through a series of improvement to provide a very accurate determination of a gravimetric geoid (Foroughi et al., 2019; Kingdon and Vaniček, 2011; Tenzer et al., 2003a; Tenzer et al., 2003b). Modern testing of the approach had been done in the last years. For example, Janák et al. (2017) demonstrated than when the approach is correctly applied the computed geoid is of the same or perhaps better accuracy than the results of other techniques. Furthermore, Foroughi et al. (2017) provide an assessment on the optimal combination of satellite data and terrestrial data and most recently they showed new advances on the algorithm for downward continuation using Least Squares and showed the likelihood of obtaining a sub-centimetric geoid (Foroughi et al., 2019). All these findings and developments assure a very precise geoid determination using the Stokes-Helmert approach. In the 
current work, the improvements carried out by Foroughi et al. (2019) were not included because of the time period of this project.

\section{Theory and methods}

The importance of gravity in height determinations is well-known. For example, we can find this effect when surveying with an automatic level (A-level). Spirit levelling is the simplest and most accurate technique for height determination. Basically, height differences are measured from point (A) to another point (B). If the gravity measurements are not performed when surveying with this technique, the heights will contain a systematic error due to non parallelism of the equipotential gravity surfaces, and the height differences obtained are only an approximation of the real change in orthometric heights - see Hofmann-Wellenhof and Moritz (2006). Fig. 1 illustrates this situation with a little exaggeration; the subtraction of the reading (Bs-R - Fs-R) is not equal to the same operation using the differences in orthometric heights $(\Delta H a-\Delta H b)$.

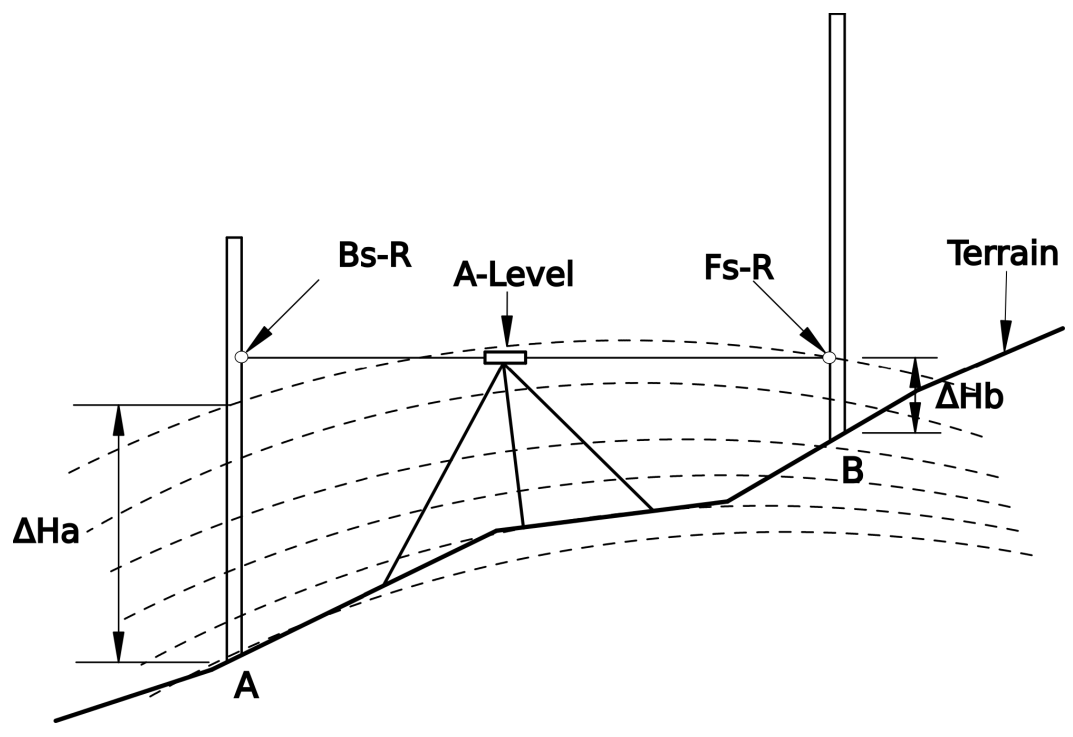

Fig. 1. The difference between the Bs-R and $\Delta H a$ illustrates the problem of physical height determination. 
To have a consistent national height system, all benchmarks (BM) must be referred to a common equipotential surface (a geoid). This is a complex situation because the survey lines run on the surface of topography while the geoid most of the time remains under the topographical surface. The situation can only be resolved with knowledge of the topographical density distribution, which has split the geodetic community over how to define a height reference surface (Vaniček et al., 2012).

As an alternative to spirit levelling, one can determine the geodetic height (h) using GNSS observations. This $\mathrm{h}$ is a geometric quantity representing a straight line from a reference ellipsoid to the point of interest. The more useful orthometric height $(H)$ is a physically meaningful height of a point above the geoid and is measured along a curved plumbline from the geoid to the surface (Hofmann-Wellenhof and Moritz, 2006). Apart from the obvious differences between them, $h$ may be considered a coarse approximation of the orthometric height that can be converted to $\mathrm{H}$ by a transformation, called the geoid-ellipsoid separation N; Eq. (1) shows the relationship between the different heights:

$H=h-N$.

\section{The disturbing potential and its relationship to the geoid}

The disturbing potential $(T)$ on the geoid is the difference between the actual gravity potential $(W)$ and the normal gravity potential $(U)$ at the same point (Heiskanen and Moritz, 1967). $N$ can be determined by means of Brun's formula if $\mathrm{T}$ is known on the geoid $\left(T_{G}\right)$ (Eq. (2) and Eq. (3)):

$T_{G}=W_{G}-U_{G}$,

$N=\frac{T}{\gamma}+\frac{W_{0}-U_{0}}{\gamma}$

$W_{0}$ and $U_{0}$ are the geoid and the ellipsoid reference equipotential values. $\gamma$ represents the normal gravity value on the ellipsoid.

If $W_{0}$ is set to be equal to $U_{0}$, the second term in Eq. (3) becomes 0 , and the computation is simplified. As $W_{G}$ is the potential on the geoid is also the same as $W_{0}$. 


\section{The UNB Stokes-Helmert approach}

The Stokes-Helmert approach has been described thoroughly by Ellmann and Vaniček (2007) and a series of other publications. Here, we provide a summary of the main concepts.

Stokes' integral (Stokes, 1849) may be used to calculate the disturbing potential on the geoid surface, using gravity anomalies provided on the geoid surface. The process of transforming anomalies values on the surface to the geoid is called downward continuation (DWNC) and the gravity values outside the geoid must be harmonic to perform DWNC correctly. If the gravity anomaly values $(\Delta g)$ are multiplied by the point's distance to the center of the Earth $(r)$, the term $r \Delta g$, which is harmonic (Huang, 2002), can be introduced in the Poisson's integral to obtain the downward continued $\Delta g$.

Inside the topographic masses the gravity potential field is not harmonic. Thus, Helmert's second condensation method is applied to allow downward continuation in this domain. In this method, the Earth's topographic and atmospheric masses are condensed to a thin layer on the geoid, transforming the gravity values to the Helmert space (see Janák et al. (2017) and Ellmann and Vaniček (2007) for more information). The Stokes' integral (Eq. 4) may then convert the downward continued gravity anomalies into disturbing potential $(T)$ and a geoid height $(N)$ may be determined, and ultimately transformed from the Helmert space, back into the real space:

$N=\frac{R}{4 \pi \gamma_{m}} \iint S(\psi) * \Delta g \mathrm{~d} \sigma$,

where $R$ is the semimajor axis of the reference ellipsoid, $\gamma_{m}$ the mean normal gravity value, $S(\psi)$ the Stokes' kernel and $\Delta g$ is the gravity anomaly (Torge and Müller, 2012).

\section{The process of geoid computation}

In addition to the main steps described so far in this document, a geoid computation involves numerous small details, which can lead to an incorrect result if neglected (see Janák et al. (2017)). Thus, to perform the computation, the researcher must thoroughly study the technique. The first step is to compute the Helmert gravity anomalies $\left(\Delta g^{H}\right)$, which are required to 
compute the disturbing potential and so the geoid. $\Delta g^{H}$ is well approximated by the widely available free-air gravity anomaly, $\Delta g^{F A}$ (Heiskanen and Moritz, 1967). Thus, the process of a geoid computation starts with the free-air gravity anomaly. A series of transformations must be applied to compute the $\Delta g^{H}$ values such as the direct topographical (DTE) and atmospheric (DAE) effects, the secondary topographical effect (SITE), and the geoid-quasigeoid correction (G-QG). Furthermore, the Helmert gravity anomalies must be downward continued to the geoid. These processes may be represented as:

$\Delta g^{F A}\left(r_{t}, \Omega\right) \rightarrow \Delta g^{H}\left(r_{t}, \Omega\right)$,

$\Delta g^{H}\left(r_{t}, \Omega\right) \rightarrow \Delta g^{H}\left(r_{g}, \Omega\right)$.

Vaníček and Sjöberg (1991) introduced the idea of splitting the determination of geoid heights in two parts. This idea allows combination of satellite and ground gravity techniques to obtain a more accurate solution, because satellite geopotential modelling describes the long wavelength of the gravity potential field using spherical harmonics coefficients, more accurately than ground measurement techniques. Thus, an accurate geoid determination must include satellite measurements. Consequently, the satellitebased Helmert anomalies $\Delta g_{s a t}^{H}$, represented by a spherical harmonic series to low (e.g. 160) degree and order are subtracted from, producing a residual Helmert gravity anomaly $\Delta g_{r e s}^{H}$ :

$\Delta g_{\text {res }}^{H}=\Delta g^{H}-\Delta g_{\text {sat }}^{H}$,

where $\Delta g_{\text {sat }}^{H}$ is computed using a global geopotential model.

A residual cogeoid height $N_{\text {res }}^{H}$, is obtained from application of Stokes' integral using $\Delta g_{\text {res }}^{H}$, and $N_{\text {sat }}^{H}$ is computed using global geopotential models (GGM). Then, the full geoid heights are found using:

$N^{H}=N_{\text {res }}^{H}+N_{\text {sat }}^{H}$.

The cogeoid quantity is the result of applying the Stokes' integral to the downward continued data, and it is not a geoid because the effects of the compression of the atmospheric and topographic masses has to be restored. In other words, these quantities are still in the Helmert space; thus, the 
primary indirect topographic (PITE) and atmospheric (PIAE) effects must be added to transform the result to the final geoid heights in the real space $(N)$.

\section{Satellite, marine, and ground data combination}

We combined several ground and marine databases to obtain the data set shown in Fig. 2. Specifically, onshore data from the National Geospatial Intelligence Agency (NGA) of the United States, onshore and offshore data from the Bureau Gravimetrique International (BGI), offshore data from the National Oceanographic and Atmospheric Agency (NOAA) of the United States, and a compilation of all the available historical gravity measurements for Costa Rica which were not contained in the previ-

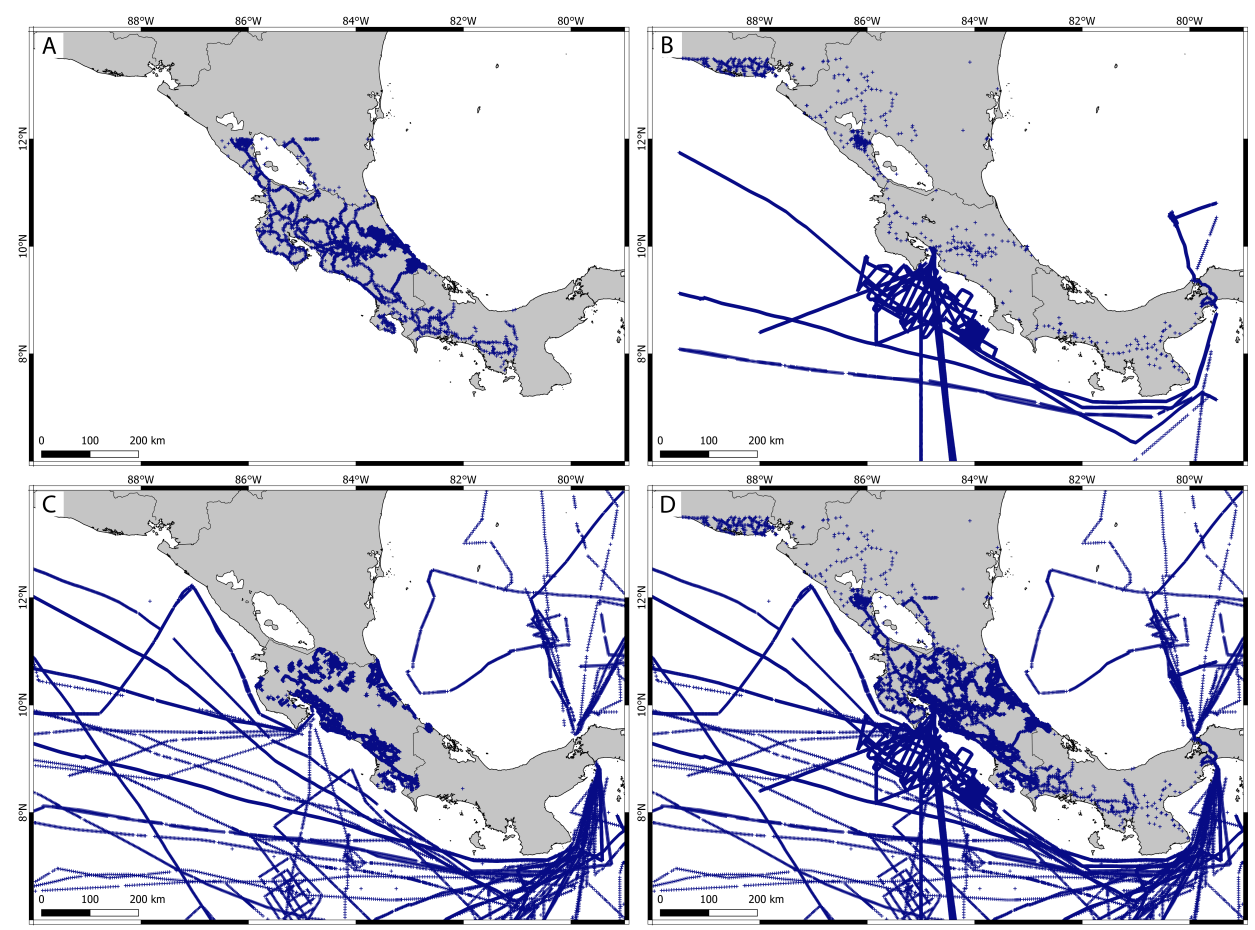

Fig. 2. Surface gravity data distribution. A: NGA database. B: BGI database, C: Costa Rica Historical Database onshore, NOAA database offshore. D: Combined quality-controlled database for calculation of GCR-RSH-2020. 
ous datasets. As quality control, we used the x2sys GMT tools to check the crossover errors of the marine gravity survey, while the ground gravity databases were compared to high degree and order GGMs and topography. To carry out this comparison, gravity disturbances $(\delta g)$ were computed in both land gravity values and GGMs. The ICGEM calculation service (http://icgem.gfz-potsdam.de/calcgrid) allows to compute the gravity disturbance quantities which uses the ETOPO1 to perform the necessary computations (Barthelmes, 2013). To make the computation of $\delta g$ of the land gravity values $\left(\delta g^{\text {Terrest }}\right)$ closer to the ones computed by the ICGEM calculation service $\left(\delta g^{\mathrm{Model}}\right)$, we estimate h by bilinear interpolation using the ETOPO1 each model and $N$ values from the geoid models grids. The residuals from the subtraction of to the would give a value that can be use to validate both the GBG and the CGMs $\left(\delta g^{D I F F}\right.$ ) (see Eq. (9)). Table 1 shows the CGMs used performed this comparison while Table 2 shows the statistics of this process. Furthermore, we assessed the land gravity values in the form of classical Bouguer anomalies $(\Delta g)$ using leave-one-out cross validation (LOOCV). Fig. 3 shows the histogram of the residuals of this validation process after removing outliers, and their statistics.

$\delta g^{D I F F}=\delta g^{\text {Terrest }}-\delta g^{\text {Model }}$.

Table 1: global geopotential models (GGM) used for the computation of gravity disturbances.

\begin{tabular}{|l|c|c|l|}
\hline Gravity Model & Degree / Order & Max. Resolution & Reference \\
\hline EGM2008 & 2190 & 5' approx. & Pavlis et al., 2012 \\
\hline Eigen-6C4 & 2190 & 5' approx. & Förste et al., 2014 \\
\hline GECO & 2190 & 5' approx. & Gilardoni et al., 2016 \\
\hline SGG-UGM-1 & 2159 & 5' approx. & Liang et al., 2018 \\
\hline
\end{tabular}

Approximately, 160000 points remained of the original 209000 after quality control. The estimated overall uncertainty of the terrestrial gravity anomalies was about $2.3 \mathrm{mGal}$, with residuals of up to $16 \mathrm{mGal}$ in magnitude. They appear to be unbiased and normally distributed. Furthermore, satellite altimetry data from Sandwell et al. (2014) was used to augment the marine gravity, excluding land values and a buffer zone of $20 \mathrm{~km}$ from the coastline. Finally, overlaid a $5 \times 5$ arc-minute grid to fill gaps in the datasets. Empty cells in this grid were filled with Bouguer gravity anoma- 
Table 2. Statistics on the gravity disturbance difference $\left(\delta g^{D I F F}\right)$ for land gravity point.

\begin{tabular}{|l|c|c|c|c|}
\hline & EGM08 & EIGEN6C4 & GECO & SGGUG \\
\hline Mean & -2.602 & -2.597 & -2.396 & -2.928 \\
\hline Median & -3.340 & -2.145 & -1.894 & -3.047 \\
\hline Min & -87.681 & -86.147 & -89.774 & -87.577 \\
\hline Max & 92.669 & 96.819 & 98.182 & 95.252 \\
\hline STD & 11.088 & 11.146 & 11.376 & 10.923 \\
\hline Range & 180.350 & -182.966 & -187.956 & 182.829 \\
\hline & $\mathrm{N}=16812$ & \\
\hline
\end{tabular}

lies $(\delta g)$ calculated from the from GECO GGM (Gilardoni et al., 2016). We chose GECO GGM for compatibility reasons in the process of satellite data combination, which is further explained in this section below. In a similar process of computation of $\delta g^{\text {Model }}, \Delta g$ values from GECO GCGM was performed using the ICGEM computation services, which approximates the quantity using the topographic spherical model ETOPO1.

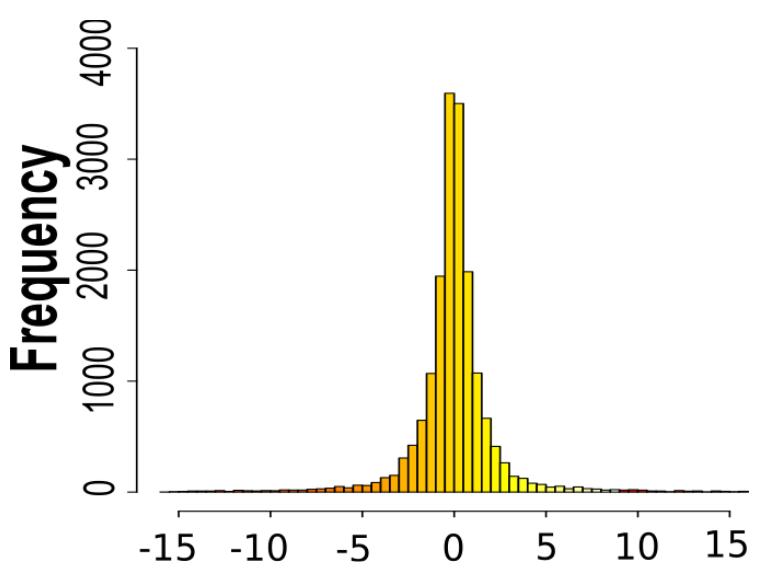

Fig. 3. The histogram shows the residuals of the LOOCV. The $x$-axis values are expressed in mGals. Statistics: Min. $-15.710,1$ st Qu. -0.670 , Median -0.006 , Mean: -0.004275 , 3rd Qu. 0.677849, Max. 15.954, Std. 2.329.

To perform the interpolation, all anomalies were converted into Bouguer anomalies and aggregated to the GECO GCGM anomalies. This interpolation was performed to simplify the process instead of the more rigorous process, using NT anomalies. We assigned weights considering the date of survey, source and measurement type. All the $\delta g$ observations were gridded 
with a $1 \times 1$ arc minute resolution using GMT-blockmean and GMT-surface in a way to prevent high frequency aliasing. Finally, the SRTM-1 (U.S. Geological Survey, n.d.) (with 1 arc-second resolution) resampled to $1^{\prime} \times 1^{\prime}$ was used to compute the free-air anomalies necessary to start the computation.

We chose the GOCO05s global satellite-only geopotential model (GSGM) as the reference field for our computation because of improvements made with the inclusion of GOCE data (Mayer-Guerr, 2015) and the compatibility with GECO GCGM previously used for filling data gaps. A degree and order of 160 was chosen as the contribution of GOCO05S. This parameter was set based on the investigations of Foroughi et al. (2017). Finally, a geoid resolution of 1 arc minute was chosen for numerical stability reasons (Foroughi et al., 2019).

\section{Validation and comparison to the global geoid models}

To test the computations, we selected 4 GCGMs, which have the highest degree and order available. For example, EGM2008 was the first high resolution global geoid model and it is still used by many institutions as standard (Pavlis et al., 2012). Eigen-6C4 and GECO contain data from the Gravity Field and Steady-State Ocean Circulation Explorer (GOCE) project (Förste et al., 2014). Moreover, GECO contains an improvement compared to EGM2008 at medium frequencies (Gilardoni et al., 2016). At last, the SGG-UGM improved the resolution of the EGM2008 using GOCE and airborne gravity data in China. Since SGG-UGM is one of the newest GGM combined models, some authors suggest it needs further testing (Liang et al., 2018). Geoid models computed from these GCGMs have a maximum spatial resolution of approximately $9 \mathrm{~km}\left(5^{\prime}\right)$.

\section{Results}

The free-air anomalies $\left(\Delta g^{F A}\right)$ are influenced by all topographic and atmospheric masses. These effects make $\Delta g^{F A}$ noisier at the topographical surface than the Helmert anomalies $\left(\Delta g^{H}\right)$, which have all these masses condensed to the geoid. Fig. 4 shows a plot of both quantities over Costa Rica, Nicaragua and Panama. One can see that $\Delta g^{H}$ are recognisably 
smoother than $\Delta g^{F A}$, especially in the mountainous areas. Also, mountainous areas present larger gravity anomalies than flatlands, as we might expect. Fig. 4 further shows the condensation process to prepare $\Delta g^{F A}$ for the downward continuation operation. As one can see, a correction for lateral topographical density variations was not included in the computation because a density model was not available at the time of the computation. Also, the Hörmander effect has not been included, but is very small compared to our expected final centimetric accuracy (see Janák et al. (2017)).

Fig. 5 shows the downward continued Helmert anomalies $\left(\Delta g_{g}^{H}\right)$. When the reference anomalies $\left(\Delta g_{s a t}^{H}\right)$ are subtracted from $\Delta g_{g}^{H}$, we obtained the residual Helmert anomalies $\left(\Delta g_{r e s}^{H}\right)$ on the geoid that are required to compute the residual cogeoid. One can notice that $\Delta g_{g}^{H}$ quantities are rougher than $\Delta g^{H}$, as expected.

Applying Stokes' integral provides the residual cogeoid, that is then added to the reference cogeoid computed from GOCO05s. This operation provides a complete cogeoid that is converted to the geoid by adding the primary indirect topographic effect (PITE) and primary indirect atmospheric effect (PIAE) to transform the resultant surface from the Helmert space to the real one. Moreover, the final geoid model is referred to the GRS80 system which has a slightly different reference geopotential value than the WGS84. Thus, the computed geoid was transformed to WGS84 using the correction to the zero degree order suggested by ICGEM Centre (see FAQ from http://icgem.gfz-potsdam.de/icgem faq.pdf). Fig. 6 shows the quantities of residual cogeoid, reference cogeoid, and final geoid. As expected, the higher $\mathrm{N}$ values are presented in the Talamanca Range and the lower values on the coastal areas. The geoid height range is $15.733 \mathrm{~m}$, where $3.032 \mathrm{~m}$ and $18.765 \mathrm{~m}$ are the lowest and highest values respectively. We called this geoid determination the 2020 Regional Stokes-Helmert Costa Rican Geoid (GCR-RSH-2020), following a Spanish abbreviation.

To validate this result, the GCR-RSH-2020 was compared to 4 GCGMs. The smallest and largest differences are approximately $0.4 \mathrm{~m}$ and $1.5 \mathrm{~m}$ respectively. In evaluating these comparisons, we must consider that the maximum spatial resolution of a GCGM is approximately $9 \mathrm{~km}$ while the computed geoid has a maximum spatial resolution of $1.8 \mathrm{~km}$. Thus, these differences might come from the GCGMs smoothing. We believe that more rigorous comparison would not be necessary because it is noticeable that 

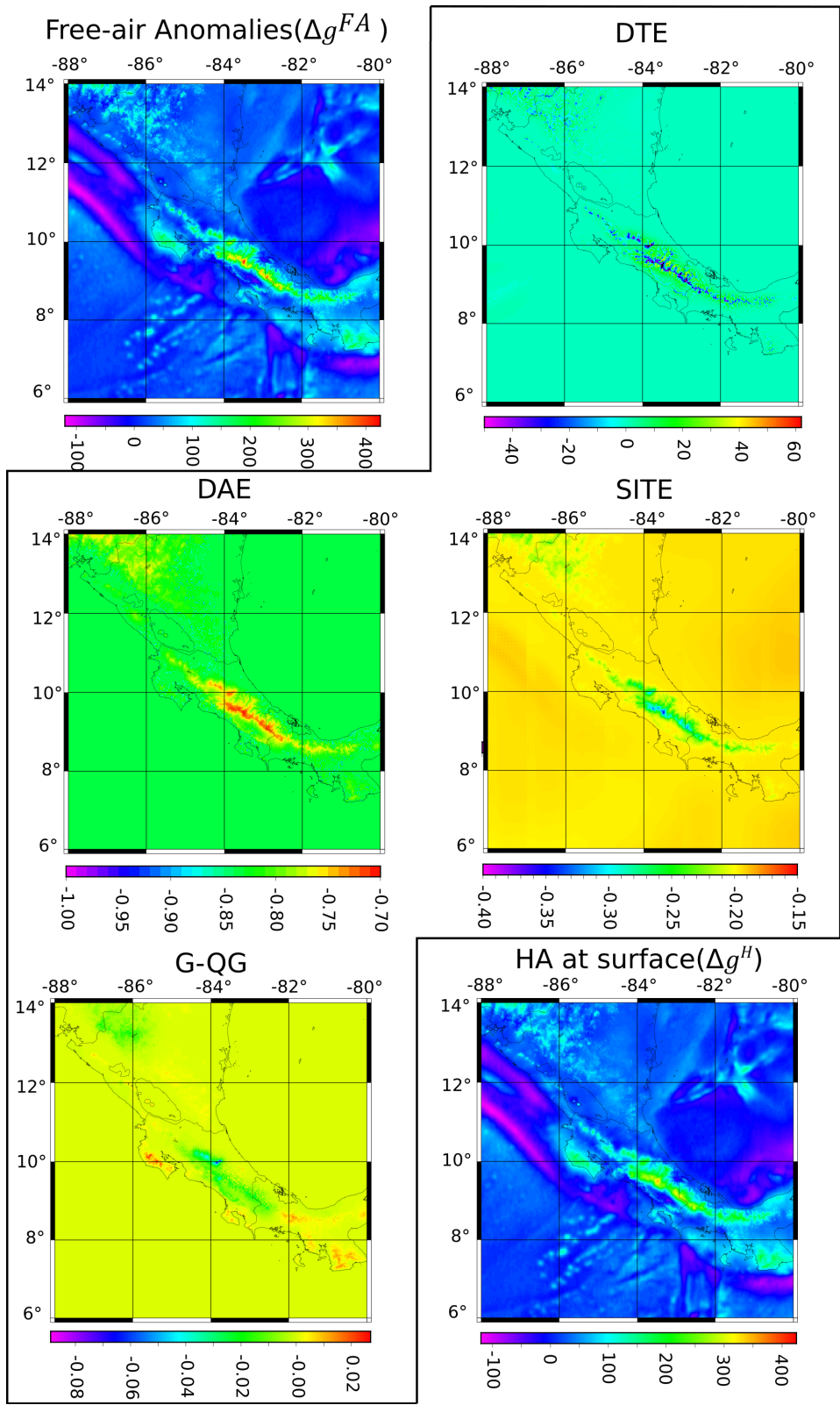

Fig. 4. The process of condensation is shown in this figure; all quantities are expressed in mGal. 


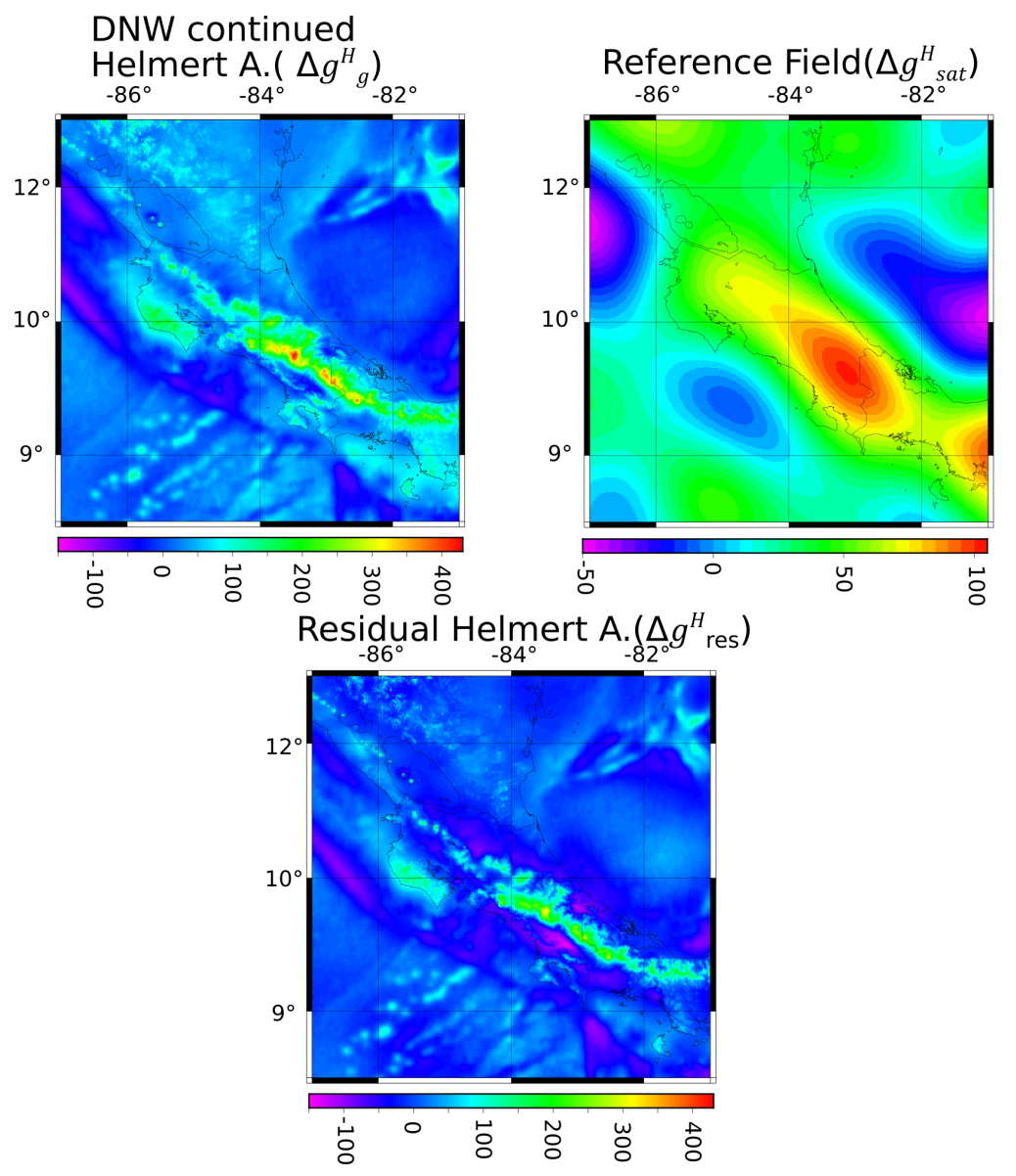

Fig. 5. The downward continued Helmert anomalies $\left(H A_{\text {geoid }}\right)$ minus the references Helmert $\left(H A_{R F}\right)$ give the residual Helmert Anomalies $\left(H A_{r e s}\right)$; all quantities are expressed in $\mathrm{mGal}$.

the main differences are in the mountainous areas and the Talamanca range. Also, the differences found in the rest of the country are centimetric.

Fig. 7 shows the subtraction of the chosen GCGM from GCR-RSH2020. As seen, the largest differences are obtained when comparing to the EGM2008 geoid. This result shows that the improvements in Costa Rica from the new models are mostly in the mountains. Other testing against models EIGEN-6C4, GECO, SGG-UGM-1 show smaller residuals, but the 

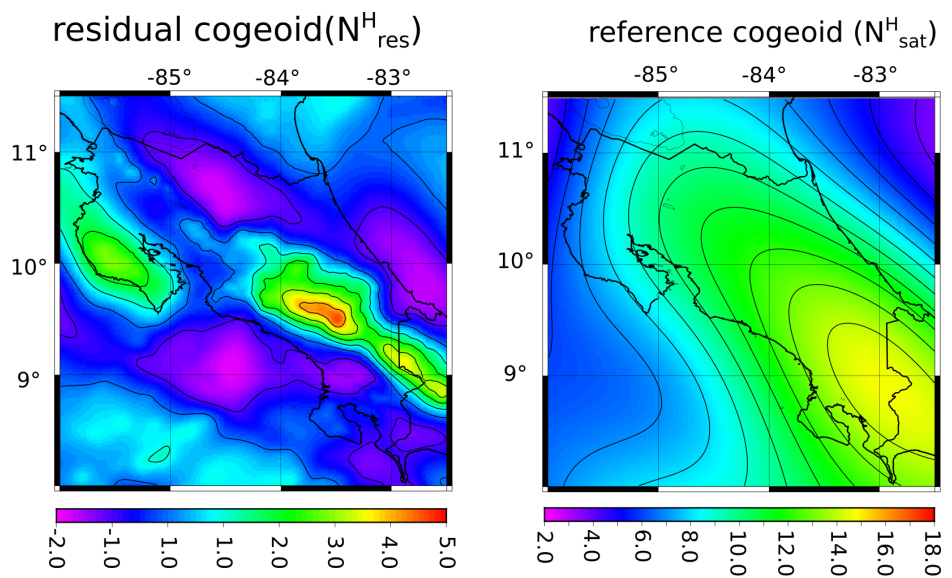

GCR-RSH-2019

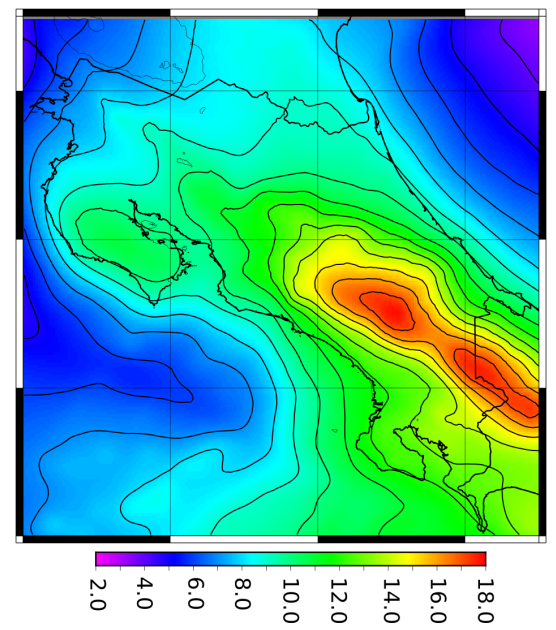

Fig. 6. Quantities of the residual cogeoid, reference cogeoid and the final geoid model. Red values represent the higher geoid heights $(N)$ while blue/violet the lower ones. The geoid is referred to WGS84. The units are metres $(\mathrm{m})$.

lowest differences are obtained in comparisons with SGG-UGM-1 and GECO (see Fig. 7). We are aware that there is a stronger correlation between our solution and these two GCGM, because they both include the new GOCE satellite gravity data. However, this also means that our solution is consistent with other modelling based on this data, and properly incorporates the improved model. 


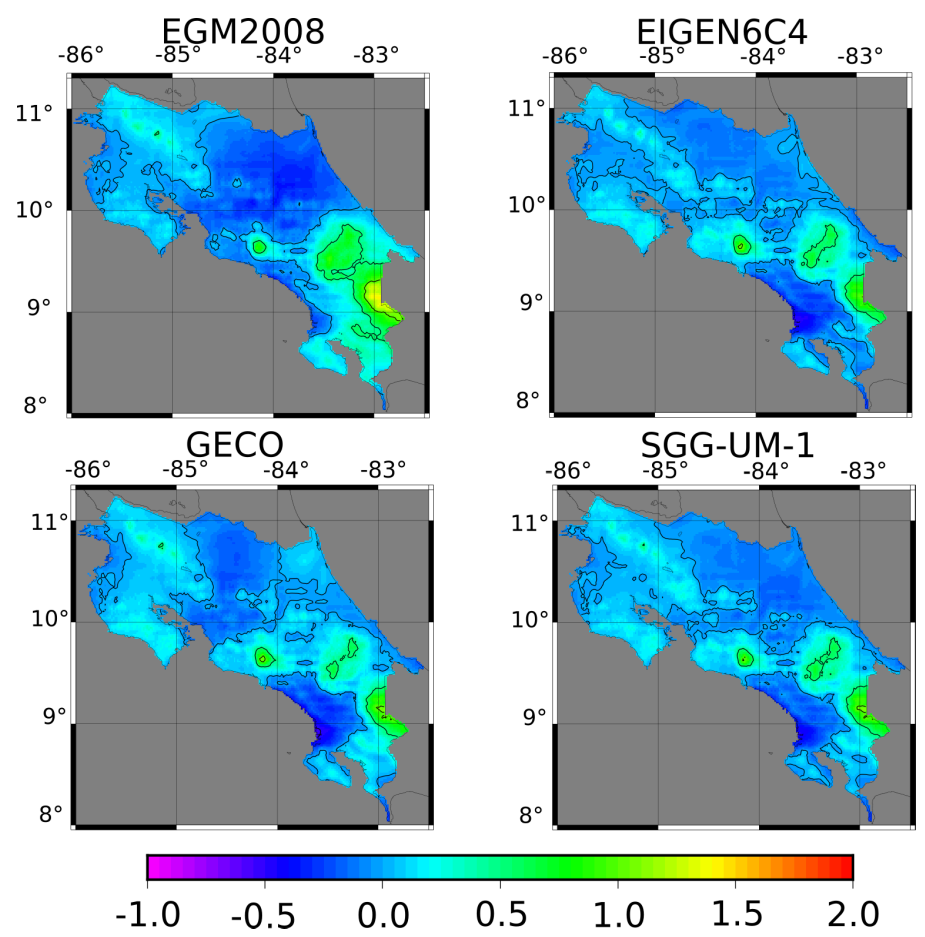

Fig. 7. The ellipsoidal height differences between GCR-RSH-2020 and each of the 4 GCGM models are presented in meters.

We computed differences from global models both including and excluding ocean areas. This process was done to know how the geoid behaves in both conditions, and to be able to isolate issues with topography and land gravity from issues with the geoid modelling as a whole. Differences from these global models should be approximately normally distributed. Fig. 8 shows a histogram of the differences when ocean values are included, i.e., when the whole onshore and offshore geoid is compared with global models. As seen, the residuals have approximately normal distribution, with longer tails extending to the right of the histogram indicating some extreme positive differences. The histograms for differences from GECO and from SGG-UM-1 are similar to one another. The statistics of these differences show a small systematic shift between the geoid and the other global geoid models (see Table 3). Also, we can conclude that the ocean determination of the $N$ values is accurate because the interquartile range is centimetric. 

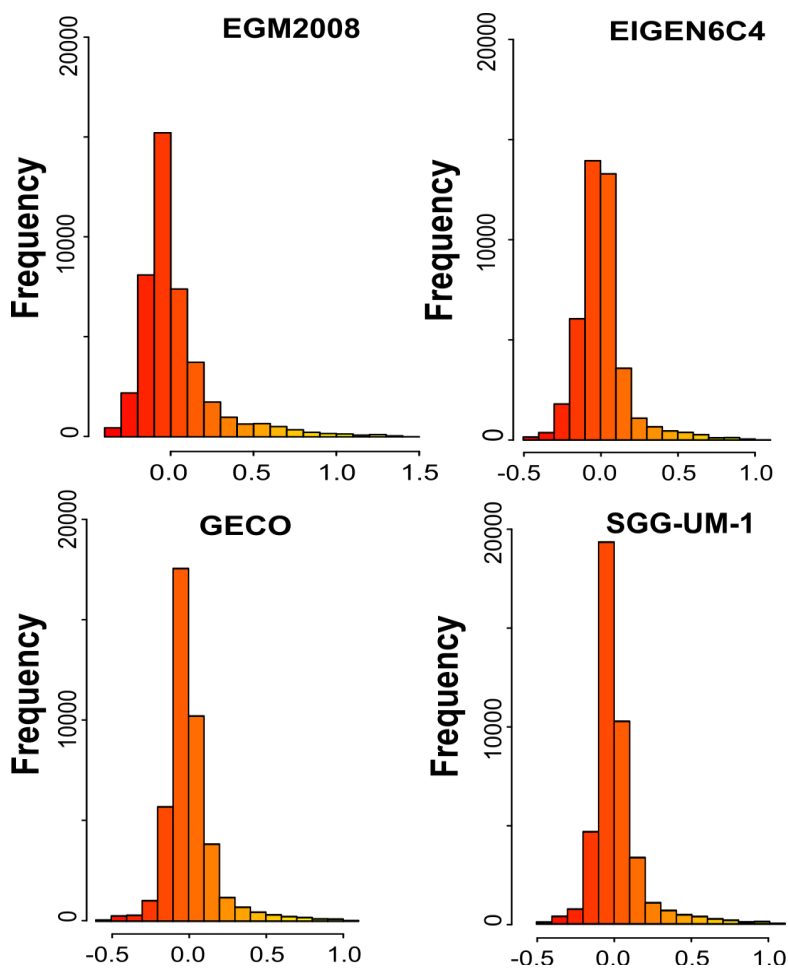

Fig. 8. The histogram of the differences between the global geoid models and GCR-RSH2020, including ocean values. Horizontal axes are in metres.

The histograms of the differences for land values (see Fig. 9) present differences in contrast to the ones show in Fig. 8. The EGM2008 differences

Table 3. Statistics of the differences between global geoid models and GCR-RSH-2020, including ocean values. All quantities are in metres.

\begin{tabular}{|l|r|r|r|r|}
\hline & EGM2008 & EIGEN6C4 & GECO & SGG-UM-1 \\
\hline Min & -0.396 & -0.494 & -0.535 & -0.464 \\
\hline Max & 1.431 & 1.065 & 1.082 & 1.088 \\
\hline 1st Qu. & -0.101 & -0.083 & -0.079 & -0.065 \\
\hline 3rd Qu. & 0.078 & 0.059 & 0.061 & 0.046 \\
\hline Median & -0.029 & -0.007 & -0.023 & -0.018 \\
\hline Mean & 0.026 & 0.006 & 0.006 & 0.012 \\
\hline Range & 1.827 & 1.559 & 1.617 & 1.552 \\
\hline Std & 0.231 & 0.162 & 0.167 & 0.162 \\
\hline
\end{tabular}


have a more substantial tail to the right while the other global geoid models have histograms approaching the normal distribution. Moreover, the statistics show a bias of approximately $5 \mathrm{~cm}$ from the global fields, but this is probably influenced by the positive tails of the histogram. The median values, when comparing to EIGEN-6C4 and SGG-UM-1, is very close to 0 (see Table 3 ). The extreme values that influence the mean value come mostly from the Talamanca mountain range and the Cerro de la Muerte region, as seen in Fig. 7, and these have a greater influence when excluding ocean values because fewer values are averaged. The minimum and maximum values from Tables 3 and 4 slightly differ due to interpolation error in the resampling process (the resolution of the GGM is about 5'), but the differences are not significant.
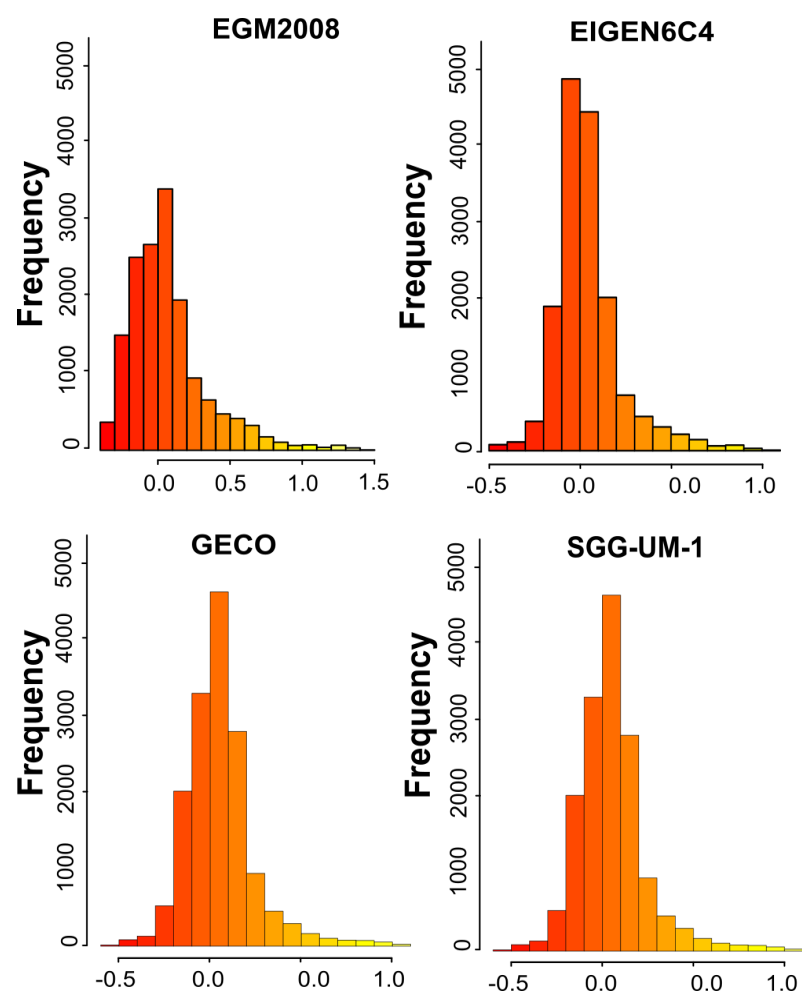

Fig. 9. The histogram of the differences between global geoid models and GCR-RSH-2020, excluding ocean values. Horizontal axes are in metres. 
Table 4. Statistics of the differences between global geoid models and GCR-RSH-2020, excluding ocean values. All quantities are in metres.

\begin{tabular}{|l|c|c|c|c|}
\hline & EGM2008 & EIGEN6C4 & GECO & SGG-UM-1 \\
\hline Min & -0.397 & -0.493 & -0.535 & -0.463 \\
\hline Max & 1.436 & 1.070 & 1.087 & 1.093 \\
\hline 1st Qu. & -0.119 & -0.064 & -0.052 & -0.070 \\
\hline 3rd Qu. & 0.159 & 0.102 & 0.126 & 0.110 \\
\hline Median & 0.023 & 0.009 & 0.042 & 0.017 \\
\hline Mean & 0.069 & 0.043 & 0.055 & 0.048 \\
\hline Range & 1.833 & 1.563 & 1.622 & 1.556 \\
\hline Std & 0.275 & 0.183 & 0.192 & 0.188 \\
\hline
\end{tabular}

The accuracy of the old Costa Rican height system is still in debate and is unknown. However, GNSS/levelling differences on 25 selected benchmarks of the old height system are the only available independent method for testing the computation. Table 5 shows the comparison of GNSS/levelling geoid-ellipsoid separations from GCR-RSH-2020 model and from the different GCGM geoids. The GNSS/levelling points were distributed evenly along the country (see Fig. 10). Consequently, a shift of $7 \mathrm{~cm}$ can be seen from the subtraction of GCR-RSH-2020 from GNSS/levelling values. This result is not surprising because the old height system was referred to an unknown reference surface tied to a tidal gauge. GCR-RSH-2020 showed a better standard deviation of differences than the GCGMs, suggesting a higher relative accuracy. However, a 5\% significant level Fisher test on the variance does not show significant differences among the models. Since all models showed a similar level of disagreement, it is likely that these variations are mainly associated with errors in the existing height system rather than in the geoid models, and this makes it difficult to draw strong conclu-

Table 5. Differences between the geoid-ellipsoid separations from GNSS/levelling and from global geoid models. All quantities are in metres. 25-point sample size.

\begin{tabular}{|l|c|r|r|r|r|}
\hline & GCR-RSH-2019 & EGM08 & Eigen6C4 & GECO & SGG-UM-1 \\
\hline Mean & 0.072 & 0.013 & 0.026 & 0.006 & 0.026 \\
\hline Min & -0.396 & -0.489 & -0.370 & -0.390 & -0.455 \\
\hline Max & 0.643 & 0.692 & 0.680 & 0.703 & 0.672 \\
\hline Median & 0.074 & -0.005 & -0.023 & -0.007 & -0.001 \\
\hline Std & 0.207 & 0.263 & 0.217 & 0.228 & 0.216 \\
\hline Range & 1.039 & 1.181 & 1.050 & 1.093 & 1.127 \\
\hline
\end{tabular}




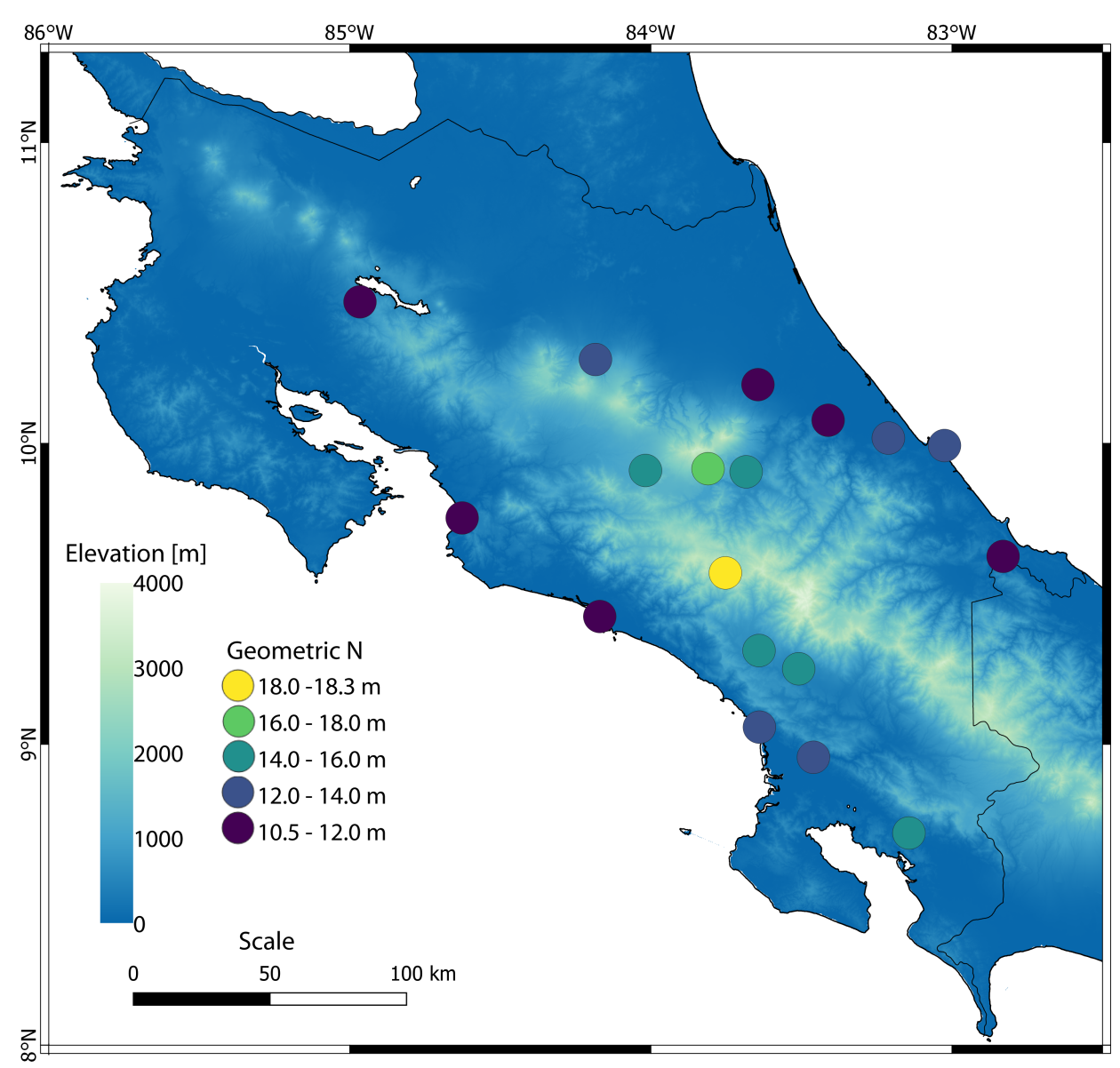

Fig. 10. GNSS/levelling geoid-ellipsoid separations. The circles show the location of the benchmarks used for validation of $\mathrm{N}$ and the resulting value.

sions from this comparison.

All the results shown above suggest that GCR-RSH-2020 is consistent with the global geoid models and is more accurate in terms of the determination of $(N)$ as well as having a better spatial resolution $(1.8 \mathrm{~km}$ compared to $9 \mathrm{~km}$ ). The analysis is limited by the small number of GNSS/levelling points for comparison and the quality of those points. The small size of the comparison area excluding ocean values limits comparisons with GCGMs as local differences, e.g. in mountain areas, significantly affect the mean differ- 
ence. There is still more work to carry out for the Costa Rica geoid determination. However, we consider our solution is accurate enough to be released to the public for validation purposes. Moreover, we will focus on gravity ground surveys for the Talamanca region and a density model to improve our geoid determination in the near future. Also, more GNSS/levelling data samples must be collected to evaluate the computation more thoroughly.

\section{Concluding remarks}

A geoid for Costa Rica was computed using the UNB Stokes-Helmert approach. This effort used data derived from satellite altimetry, marine gravity surveys, and terrestrial gravity surveys, which were transformed to the Helmert anomalies derived from the free-air anomalies. We downward continued the data from the physical surface of the Earth to the geoid and filled any data gaps with the GECO GCGM. An interpolation process was performed using Bouguer anomalies to reconstruct a regular grid of $1^{\prime} \times 1^{\prime}$ resolution, using the SRTM1 DTM. The final $\Delta g^{F A}$ values matched with the Costa Rican topography and the geological structures. Thus, we confirmed that the interpolation process was reasonable. The computed 2020 Regional Stokes-Helmert Costa Rican Geoid (GCR-RSH-2020) has maximum and minimum values of $15.733 \mathrm{~m}$ and $3.032 \mathrm{~m}$ using the WGS84 vertical reference geopotential value. GCR-RSH-2020 was consistent with GCGMs over a large area. Values over land only appeared biased relative to the tested GCGMs, but the small area tested limits the meaningfulness of such analysis. The GECO and the SGG-UM-1 GCGMs presented a better agreement with the geoid model based on histograms and the statistics. The maximum and minimum values of the differences are approximately $1.5 \mathrm{~m}$ and $-0.5 \mathrm{~m}$ approximately with the largest discrepancies in the mountainous areas, where global models and gravity data are both likely to be of lower quality. Approximately, a $5 \mathrm{~cm}$ shift was found in the difference between of geoid values over land from the GCGM and the GCR-RSH-2019 models, largely because the GCR-RSH-2020 model was higher in mountainous areas. This disagreement in the mean is possible despite the inclusion the GOCO satellite-only global geopotential model, which improves the lower frequencies of the geoid, because the inclusion of the better distributed and high quantity land data might have an effect in this systematic shift. When com- 
pared with GNSS/levelled geoid-ellipsoid separations, the smallest variance was given by GCR-RSH-2020. This result shows that the GCR-RSH-2020 is at least as accurate as the tested GCGMs, but there are no statistical differences in the variances of these models based on the Fisher test on the variance. The model GCR-RSH-2020 also represents an improvement in terms of spatial resolution. A greater number of GNSS/levelling data samples would allow to test the variances more adequately, and these tests would be more meaningful if compared against a more precise levelling datum. In the future, we are working on a density model and collecting more gravity ground data especially in the Talamanca range and Cerro de la Muerte region to improve future geoid computation as well as more GNSS observations on levelled bench marks for validation.

Acknowledgements. We acknowledge the contribution of the National Geospatial Intelligence Agency (NGA) of the United States, the Bureau Gravimétrique International (BGI), and CENIGA for the provided gravimetric data, which is an important part of this research. This article is a contribution to the Surveying Engineering School's project 341-B6-538 part of the research program Red Sismológica Nacional of the University of Costa Rica.

\section{References}

Ballestero C. L. E., Dobrinescu M. M., Jager G. C., Mayers I. R., 1995: An Integrated Geological and Geophysical Interpretation of the San Carlos Basin, Costa Rica. In: Miller R. L., Escalante G., Reinemund J. A., Bergin M. J. (Eds.): Energy and Mineral Potential of the Central American-Caribbean Region. Berlin, Heidelberg: Springer Berlin Heidelberg, 95-103, doi: 10.1007/978-3-642-79476-6_11.

Barritt S., Berrangé J., 1987: Interpretation of a Gravity Survey of the Osa Peninsula and environs, Southern Costa Rica. Overseas Geology and Mineral Resources, No. 64, British Geological Survey.

Barthelmes F., 2013: Definition of functionals of the geopotential and their calculation from spherical harmonic models: theory and formulas used by the calculation service of the International Centre for Global Earth Models (ICGEM). http://icgem.gfzpotsdam.de/ICGEM/, revised Edition, (Scientific Technical Report, 09/02), Potsdam: Deutsches GeoForschungsZentrum GFZ, 32 p., doi: 10.2312/GFZ.b103-0902-26.

Cordero Gamboa G., 2010: Development of the CGV08 geoid model as a contribution to the determination of a national geoid (Desarrollo de un modelo geoidal CGV08 como insumo para la determinación nacional del geoide). Uniciencia, 24, 1, 35-40 (in Spanish). 
de Boer J., 1974: Mapa geofísico preliminar de Costa Rica - Escala 1:500 000. San Jose, Costa Rica: Instituto Geográfico Nacional de Costa Rica (in Spanish).

Denyer P., Vargas C., Lücke O. H., Solano J., 2019: Deformation and Geomorphology (Deformación y Geomorfología). In: Denyer P. (Ed.): Geological perspective of northwestern Costa Rica: History, Evolution and Cartography (Perspectiva Geológica del Noroeste de Costa Rica. Historia, Evolución y Cartografía), 1st ed., 26 p., San Jose, Costa Rica: Editorial Universidad de Costa Rica (in Spanish).

Ellmann A., Vaníček P., 2007: UNB application of Stokes-Helmert's approach to geoid computation. J. Geodyn., 43, 2, 200-213, doi : 10.1016/j.jog.2006.09.019.

Foroughi I., Vaníček P., Kingdon R. W., Goli M., Sheng M., Afrasteh Y., Novák P., Santos M. C., 2019: Sub-centimetre geoid. J. Geod., 93, 6, 849-868, doi: 10.1007/s00190018-1208-1.

Foroughi I., Vaníček P., Novák P., Kingdon R. W., Sheng M., Santos M. C., 2017: Optimal Combination of Satellite and Terrestrial Gravity Data for Regional Geoid Determination Using Stokes-Helmert's Method, the Auvergne Test Case. In: Vergos G. S., Pail R., Barzaghi R. (Eds.): International Symposium on Gravity, Geoid and Height Systems 2016, 37-43, Springer, doi : 10.1007/1345_2017_22.

Förste C., Bruinsma S., Abrikosov O., Flechtner F., Marty J.-C., Lemoine J.-M., Dahle C., Neumayer H., Barthelmes F., König R., Biancale R., 2014: EIGEN-6C4 - The latest combined global gravity field model including GOCE data up to degree and order 1949 of GFZ Potsdam and GRGS Toulouse. In: EGU General Assembly Conference Abstracts, EGU General Assembly 2014, Vienna, 16, 3707.

Gilardoni M., Reguzzoni M., Sampietro D., 2016: GECO: a global gravity model by locally combining GOCE data and EGM2008. Studia Geophys. et Geod., 60, 2, 228-247, doi: 10.1007/ s11200-015-1114-4.

Gurney S., 1997: Geophysical reconnaissance of the Golfo Dulce drainage basin and environs of Costa Rica. Thesis, University of Toledo.

Heiskanen W. A., Moritz H., 1967: Physical Geodesy. W. H. Freeman and Company, San Francisco.

Hofmann-Wellenhof B., Moritz H., 2006: Physical geodesy. Springer-Verlag Vienna, Science \& Business Media, 403 p., doi: 10.1007/978-3-211-33545-1.

Huang J., 2002: Computational Methods for the Discrete Downward Continuation of the Earth Gravity and Effects of Lateral Topographical Mass Density Variation on Gravity and the Geoid. Ph.D. dissertation, Department of Geodesy and Geomatics Engineering, Technical Report No. 216, University of New Brunswick, Fredericton, New Brunswick, Canada, 141 p.

Janák J., Vaníček P., Foroughi I., Kingdon R., Sheng M. B., Santos M. C., 2017: Computation of precise geoid model of Auvergne using current UNB Stokes-Helmert's approach. Contrib. Geophys. Geod., 47, 3, 201-229, doi : 10.1515/congeo-2017-0011.

Kingdon R., Vaníček P., 2011: Poisson downward continuation solution by the Jacobi method. J. Geod. Sci., 1, 1, 74-81, doi : 10.2478/v10156-010-0009-0.

Liang W., Xu X., Li J., Zhu G., 2018: The determination of an ultra high gravity field model SGG-UGM-1 by combining EGM2008 gravity anomaly and GOCE observa- 
tion data. Acta Geod. et Cartogr. Sin., 47, 4, 425-434, doi: 10.11947/j . AGCS. 2018 .20170269 .

Lücke O. H., 2018: Geophysics and geodynamics of the volcanic arc in Costa Rica (Geofísica y geodinámica interna del arco volcánico en Costa Rica). San Jose, Costa Rica, https://vinv.ucr.ac.cr/sigpro/web/projects/B5A00 (in Spanish).

Mayer-Guerr T., 2015: The combined satellite gravity field model GOCO05s. In: EGU General Assembly Conference Abstracts, EGU General Assembly 2015, Vienna, 17, 12364 .

Monges J., 1958: Isoanomalías Bouguer de la gravedad - Escala 1:2000 000. San Jose, Costa Rica: Instituto Geográfico de Costa Rica (in Spanish).

Morelli C., Gantar C., T. Honkasalo T., McConnell R. K., Tanner J. G., Szabo B., Uotila U., Whalen C. T., 1972: The International Gravity Stadardization Net 1971. Osservatorio Geofisico Sperimentale, Trieste, https://apps.dtic.mil/dtic/tr/full text/u2/a006203.pdf.

Moya Zamora J., Dörries E., 2004: A study of the geoid undulation (Estudio de la ondulación del Geoide). Uniciencia, 21, 1, 151-155 (in Spanish).

Pavlis N. K., Holmes S. A., Kenyon S. C., Factor J. K., 2012: The development and evaluation of the Earth Gravitational Model 2008 (EGM2008). J. Geophys. Res.: Solid Earth, 117, B4, doi: 10.1029/2011jb008916.

Sandwell D. T., Müller R. D., Smith W. H. F., Garcia E., Francis R., 2014: New global marine gravity model from CryoSat-2 and Jason-1 reveals buried tectonic structure. Science, 346, 6205, 65-67, doi: 10.1126/science.1258213.

Stokes G. G., 1849: On the variation of gravity on the surface of the Earth. Trans. Cam. Phil. Soc., 8, 672-695.

Tenzer R., Vaníček P., Novák P., 2003a: Far-zone contributions to topographical effects in the Stokes-Helmert method of the geoid determination. Studia Geophys. et Geod., 47, 3, 467-480, doi: 10.1023/A: 1024799131709.

Tenzer R., Vaníček P., van Eck van der Sluijs S., Hernández-Navarro A., 2003b: On some numerical aspects of primary indirect topographical effect computation in the Stokes-Helmert theory of geoid determination. Rev. Cartogr., 76-77, 71-78.

Torge W., Müller J., 2012: Geodesy. 4th Edition, Walter de Gruyter, Berlin. doi : 10.15 15/9783110250008.

U. S. Geological Survey (n.d.): USGS EROS Archive - Digital Elevation - Shuttle Radar Topography Mission (SRTM) 1 Arc-Second Global. Earth Resources Observation and Science (EROS) Center, doi: 10.5066/F7PR7TFT.

Vaníček P., Kingdon R., Santos M., 2012: Geoid versus quasigeoid: a case of physics versus geometry. Contrib. Geophys. Geod., 42, 1, 101-118, doi: 10.2478/v10126-012-00 04-9.

Vaníček P., Kleusberg A., 1987: The Canadian geoid-Stokesian approach. Manuscr. Geod., 12, 2, 86-98.

Vaníček P., Sjöberg L. E., 1991: Reformulation of Stokes's Theory for Higher than Second Degree Reference Field and Modification of Integration Kernels. J. Geophys. Res.: Solid Earth, 96, B4, 6529-6539, doi : 10.1029/90JB02782. 
Varela Sánchez M., 2018: Establishment of a tool for the re-definition of the height system for Costa Rica by means of a static gravimetric geoid (Establecimiento de una herramienta para la redefinición del sistema de alturas de Costa Rica mediante la obtención de un geoide gravimétrico estático). Ph.D. Thesis, National University of Rosario, Argentina (in Spanish). 